\title{
Newly entered medical students' views on an Information Communication Technology course
}

\author{
Dr. H.K. Wijayarathne MBBS \\ Lecturer, Faculty of Medicine and Allied Sciences, Rajarata University of Sri Lanka, Anuradhapura, Sri Lanka \\ E-Mail address: kalumwijaya@gmail.com
}

\section{Dr. V.R. Walpola MBBS}

Lecturer, Faculty of Medicine and Allied Sciences, Rajarata University of Sri Lanka, Anuradhapura, Sri Lanka E-Mail address: vwalpola.med@rjt.ac.lk

\author{
Dr. A.M.P. Mahamithawa MBBS \\ Lecturer, Faculty of Medicine and Allied Sciences, Rajarata University of Sri Lanka, Anuradhapura, Sri Lanka \\ E-Mail address: mahamithawa.med@rjt.ac.lk
}

\section{Dr. D.G.D.P.D.S. Bandara MBBS}

Lecturer, Faculty of Medicine and Allied Sciences, Rajarata University of Sri Lanka, Anuradhapura, Sri Lanka E-Mail address: danushka@techemail.com

\section{Dr. B.T.B. Wijerathne MBBS}

Lecturer, Faculty of Medicine and Allied Sciences, Rajarata University of Sri Lanka, Anuradhapura, Sri Lanka E-Mail address: buddhikatbw@gmail.com

Sri Lanka Journal of Bio-Medical informatics 2012;3(3):97-100

doi: http://dx.doi.org/10.4038/sljbmi.v3i3.5280

\begin{abstract}
Even though Information and Communication Technology (ICT) has a relatively short history, it has become a part of the medical industry, not only in selected areas of high technology medicine, but throughout the industry. Apart from using IT for medical education, it has become a mandatory element in modern medical and surgical practice. Therefore, an ICT course was designed for the new entrants of the Faculty of Medicine and Allied Sciences, Rajarata University of Sri Lanka and the perception of students on the course was evaluated using a validated questionnaire. The results of this study confirmed that the course was well organised and interesting but the time allocated for the course needs to be increased.
\end{abstract}

Keywords - Information Technology; ICT course; Medicine; Rajarata University of Sri Lanka

\section{Background}

Medical education is complex. Its goal is to provide students with sufficient conceptual information and clinical reasoning tools to ensure the competency of its graduates ${ }^{(1)}$. Today, this task is challenging because of the exponential growth in biomedical information and the time pressure experienced by medical educators. Electronic tools have the capacity to facilitate medical education, as well as to fundamentally improve our ability to ensure the competency of the medical under-graduates ${ }^{(2)}$. Based on classroom teaching experience, it is concluded that the teaching of basic information technology needs to be integrated into medical studies to improve student performance ${ }^{(3,4)}$.

ICT has made a great impact on medical practice, not only in selected areas of high-tech medicine, but in the entire field. The value of ICT lies in its ability to store, analyse, and communicate large amounts of information at very high rates of speed. These capabilities 
translate into a number of potential advantages for developing medical devices. In order to use them effectively and efficiently, medical officers should have competency in $\operatorname{ICT}^{(5)}$. Therefore,medical students must have a certain level of ICT awareness to build a successful carrier.

\section{Materials and method}

An ICT programme was designed for new entrants to the Faculty of Medicine and Allied Sciences, Rajarata University of Sri Lanka to be followed during their orientation programme from November 2009 to February 2010. After following the ICT programme, a feedback was obtained from new entrants using a validated questionnaire.

\section{Results}

A total of 183 students responded. The responses given by students about different aspects of the course are in figure 1. The responses given by students about the overall ICT programme is in table 1 .

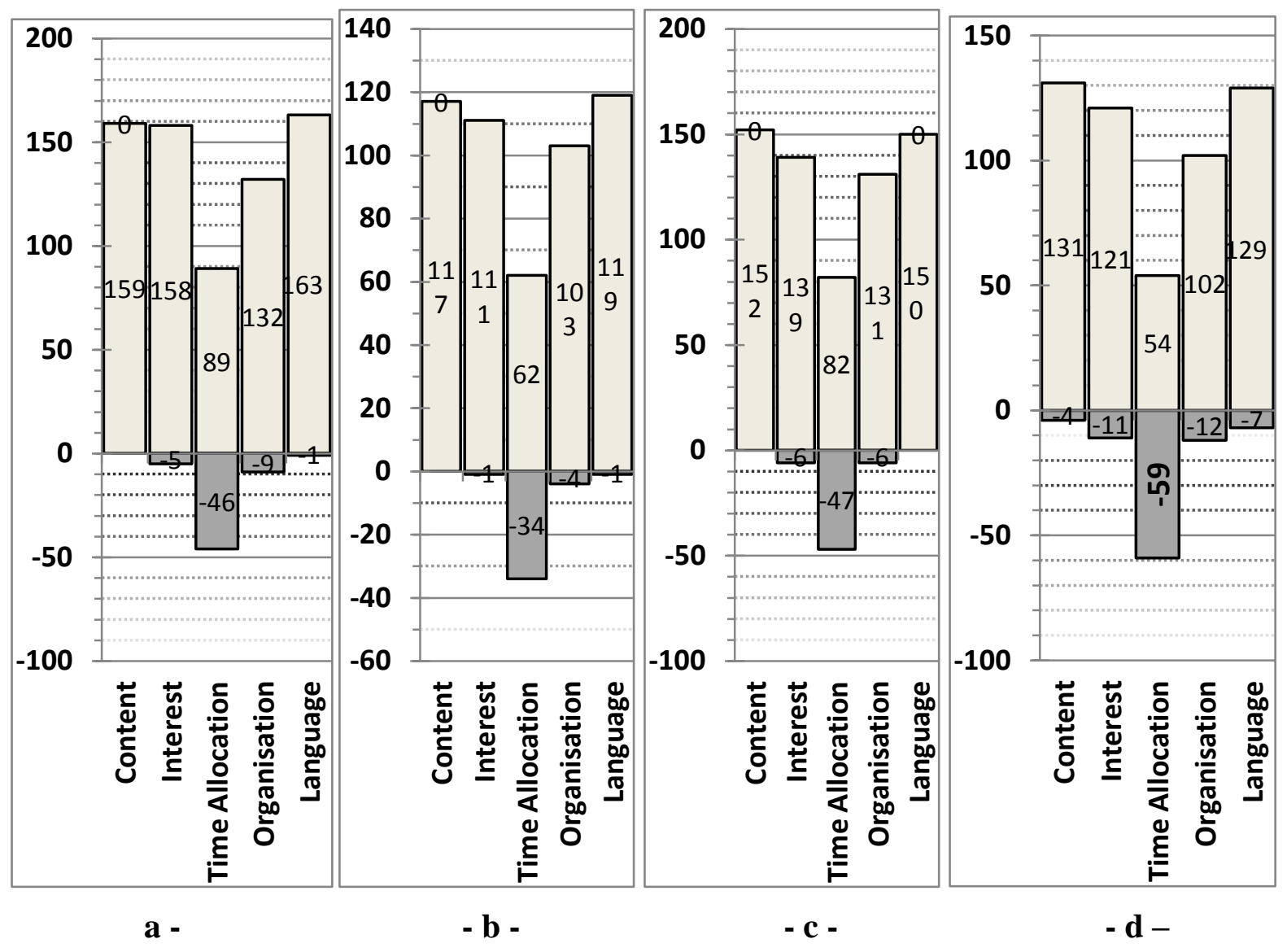

Figure 1. Responses of students for questions on each module.

a: Word processing, b: Presentation designing, c: Data management and analysis d: Networking and Internet

Agree Disagree 
Results show that $91.3 \%$ agreed that contents of lectures and discussions were useful. While $84.6 \%$ felt that the teaching sessions were interesting. Only $30.6 \%$ felt that the time allocation for modules was sufficient. About $77 \%$ concluded that it was a well organised programme. while $95.6 \%$ found the language used in teaching easy to understand.

\begin{tabular}{|c|c|c|c|c|c|}
\hline & 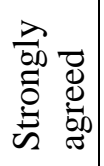 & 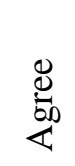 & 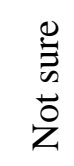 & 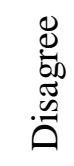 & 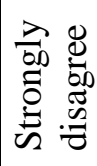 \\
\hline Contents of the lectures and the discussions were useful & 92 & 77 & 14 & 0 & 0 \\
\hline Teaching sessions were interesting & 62 & 93 & 20 & 6 & 2 \\
\hline Time allocated for modules is enough & 28 & 28 & 58 & 39 & 30 \\
\hline Teaching was conducted in a well organised manner & 52 & 89 & 29 & 8 & 3 \\
\hline Language was easy to understand & 81 & 94 & 8 & 0 & 0 \\
\hline
\end{tabular}

Table 1. Responses of students for questions on the overall ICT programme.

\section{Discussion}

Use of ICT as a tool to support medical teaching and learning was newly introduced at Faculty of Medicine and Allied Sciences, Rajarata University of Sri Lanka. Similar trends have been reported in other universities in Sri Lanka ${ }^{(6)}$. In our study we observed that most students accepted the novel ICT method.Most of the students accepted the contents, teaching methods, organisation and language of the course but not the allocated time for each module especially in 'Networking and Internet' module.Implementing new ICT programmewill be costly initially but once established it could be used for future students as well.Instructors also should be thorough when teaching ICT to students.

\section{Conclusion}

The majority of students felt that the course was well organised and used a simple language which resulted in very interesting teaching sessions. The contents of the course were very useful and they requested that the time allocated for the overall course be increased. Therefore, the programme needs to be further modified considering the above identified drawbacks. This will help develop an effective ICT programme for the next entrants.

\section{References}

1. Stern SDC. Computer-Assisted Medical Education: Current and Potential Roles 2008; 51: 22-30.

doi: http://dx.doi.org/10.1353/pbm.2008.0014

2. Piemme TE. Computer-Assisted Learning and Evaluation in Medicine. Journal of the American medical Association 1988; 260(3): 367-72.

doi: http://dx.doi.org/1001/jama.1988.03410030083033 
3. Jirhandeh NA, Haywood J. Computer awareness among medical students: a survey. Medical Education 1997; 31: 225-9.

4. Greenhalgh T. Computer assisted learning in undergraduate medical education. BMJ 2001; 322: 40-4.

doi: http://dx.doi.org/10.1136/bmj.322.7277.40

5. Lacher D, Nelson E, Bylsma E, Spena R. Computer use and needs of internists: a survey of members of the American College of Physicians-American Society of Internal Medicine. Europe PubMed Central 2000; 453-6.

6. Kommalage M, Gunawardena S. Feasibility of introducing information technology-based activities into medical curricula in developing countries. Medical Education 2008; 42(1): 113.

doi: http://dx.doi.org/10.1111/j.1365-2923.2007.02906.x 